\title{
Perancangan Sistem Keamanan Sepeda Motor Menggunakan Gps Tracker Berbasis Mikrokontroler Pada Kendaraan Bermotor
}

\author{
Hasbu Naim Syaddad \\ Program Studi Teknik Informatika \\ Fakultas Teknik Universitas Suryakancana
}

\begin{abstract}
Motor Vehicles are vehicles driven by technical equipment for their movement, and are used for land transportation. In the use of a vehicle required a security one form of security that is required at this time is the security of a transport vehicle like a motorcycle.

At this time the security of the vehicle using the type of security. Electricity and non-electricity such as handlebar locks, ignition locks up to alarms mounted on motorcycles so the owner of the vehicle can not monitor the vehicle at any time. it is also difficult to know the vehicle theft opportunities and can not know the position of the motor vehicle

In making this system using system development method based on Prototype paradigm consist of Communication, Quick Design, Quick Design, Prototype Construction and Deployment Delivery \& Feedback while for system design using UML and Flowchart. The device used is an arduino microcontroller that can be tried with other sensor sensors, as well as using mobile-based applications for the security system's security media

The results of this study are implemented into a precise positioning method using an arduino microcontroller that can control the vehicle remotely and can know the position of the vehicle. so it is expected to reduce the action pencurian that currently many occur.
\end{abstract}

Keywords : Kendaraan Bermotor,Posisi kendaraan, Keamanan, Arduino,

\begin{abstract}
Abstrak
Kendaraan Bermotor adalah kendaraan yang digerakkan oleh peralatan teknik untuk pergerakannya, dan digunakan untuk transportasi darat. Dalam penggunaanya sebuah kendaraan diperlukan sebuah keamanan salah satu bentuk keamanan yang diperlukan pada saat ini adalah keamanan pada sebuah kendaraan transportasi seperti pada sepeda motor.

Pada saat ini kemanan kendaraan menggunakan jenis kemanan berupa electric maupun non electric seperti kunci stang, penutup kunci kontak sampai dengan alarm yang terpasang pada sepeda motor sehingga pemilik kendaraan tersebut tidak dapat memonitoring kendaraan setiap saat. serta kesulitan untuk mengetahui apabila terjadi pencurian kendaraan dan tidak dapat mengetahui posisi kendaraan bermotor

Dalam pembuatan sistem ini menggunakan metode pengembangan sistem berdasarkan paradigma Prototype yang terdiri dari Communication, Quick Plan, Modeling Quick Design, Construction Of Prototype dan Deployment Delivery \& Feedback sedangkan untuk metode perancangan sistem menggunakan UML dan Flowchart. Perangkat yang digunakan merupakan microcontroller arduino beserta sensor-sensor lainnya, serta menggunakan aplikasi berbasis mobile untuk media pengendalaian sistem keamanan tersebut

Hasil dari penelitian ini diimplementasikan menjadi sebuah sistem keamanan kendaraan dengan metode precise point positioning menggunakan mikrokontroler arduino yang dapat mengendalikan kendaraan dari jarak jauh dan dapat mengetahui posisi kendaraan tersebut. sehingga diharapkan dapat mengurangi tindak pecurian yang saat ini banyak terjadi.
\end{abstract}

Kata kunci: Kendaraan Bermotor,Posisi kendaraan, Keamanan, Arduino

\section{Pendahuluan}

Precise Point Positioning merupakan metode yang di gunakan untuk mendapatkan titik posisi yang di hasilkan dari sistem pengolahan data GPS yang dilakukan secara real time. Adapun Global Positioning System atau yang lebih dikenal dengan GPS itu sendiri adalah sistem untuk menentukan letak di permukaan bumi dengan bantuan penyelarasan (synchronization) sinyal satelit (Winardi, 2006), sistem navigasi yang menggunakan satelit yang didesain agar dapat menyediakan posisi secara instan, kecepatan dan informasi waktu di hampir semua tempat di muka bumi, setiap saat dan dalam kondisi cuaca.Tujuan awal dibuatnya GPS yaitu untuk keperluan militer, baik untuk menunjukkan posisi secara tepat (positioning), membantu dalam memberikan arah (navigation), dan sistem, untuk menggantikan Transit dan juga sistem navigasi lainnya. Adapun dalam penggunannya GPS bisa digabungkan dengan sebuah alat mikrokontroler sebagai alat pengendalinya. Mikrokontroller itu sendiri merupakan komputer didalam chip yang digunakan untuk mengontrol peralatan elektronik yang mempunyai masukan dan keluaran serta kendali yang mengatur komponen lain yang terhubung dengannya. Keamanan diambil dari kata aman yang memiliki ari bebas, terlindung dari bahaya, 
tidak membahayakan. Sedangkan keamanan memiliki arti suasana aman ketenteraman, ketenangan (Peter Salim, 2002). Salah satu bentuk keamanan yang diperlukan pada saat ini adalah keamanan pada sebuah kendaraan transportasi seperti pada sepeda motor.

Menurut data yang diambil dari Badan Pusat Statisitik (BPS) jumlah pengguna sepeda motor di indonesia mengalami peningkatan dari tahun ketahunnya dimana pada tahun 2013 jumlah pengguna sepeda motor berjumlah 84.732 .652 unit, 2014 mengalami peningkatan sebanayak 92.976.240 unit, sedangkan pada tahun 2015 mengalami kenaikan sebesar 12\% menjadi 98.881.267. Dengan terjadinya kenaikan pengguna sepeda motor di indonesia mengindikasikan bahwa kendaraan bermotor mulai menjadi kebutuhan primer bagi masyarakat. Berbanding lurus dengan peningkatan pengguna sepeda motor, peningkatan kriminalitas pada pencurian sepeda motor pun mengalami peningkatan pada tiap tahunnya dimana pada tahun 2013 berjumlah 42.508 kasus yang mana memiliki peningkatan sebesar $16,98 \%$ dari tahun sebelumnya yang memiliki jumalah 41.816 kasus. meski telah terdapat sistem keamanan baik itu berupa electric maupun non electric seperti kunci stang, penutup kunci kontak sampai dengan alarm yang terpasang pada sepeda motor.

Berdasarkan permasalahan di atas maka dari itu perlu penanganan keamanan yang berlapis agar mengurangi tindak kriminalitas pencurian sepeda motor yaitu dengan memanfaatkan alat GPS yang bisa diterapkan langsung pada sepeda motor dengan bantuan sebuah kendali mikrokontroller, agar dapat menerima pesan dari GPS tersebut maka diperlukan juga modul GSM yang mana fungsinya untuk menerima infromasi mengenai keberadaan posisi sepeda motor. Selain dapat mengirimkan lokasi sepeda motor dapat juga menonaktifkan mesin motor dengan mengirimkan sebuah pesan sms pada modul GSM yang tersimpan di mikrokontroller.

Maksud penelitian adalah membangun sebuah sistem keamanan pada kendaraan dengan menerapkan metode precise point positioning untuk pencarian posisi kendaraan. Tujuannya adalah :
a. Mengurangi tindak pencurian kendaraan bermotor
b. Agar dapat mengetahui posisi kendaraan
c. Mengontrol kendaraan dari jarak jauh
d. Menambahkan komponen keamanan pada sepeda motor
Berikut ini adalah metode yang digunakan dalam penelitian ini:

1. Data yang diperlukan

Mengumpulkan informasi dan mempelajari hal hal yang berkaitan dengan jaringan kelistrikan kendaraan, sistem keamanan alarm, Tracking System, Ublox NEO-6M, SIM900A, SMS Gateway dan microkontroller Arduino.

2. Metode Pengumpulan Data

Data dikumpulkan melalui beberapa metode yaitu :

a. Studi lapangan ( observasi ), dilakukan untuk mengetahui informasi- informasi untuk bahan analisa. b. Wawancara, dilakukan dengan pihak-pihak yang terkait sebagai salah satu dasar analisa

c. Studi literatur dilakukan untuk bahan pertimbangan dalam membuat laporan dan hasil analisis.

Dalam pengembangan sistem diperlukan suatu metode perancangan yang digunakan untuk menghasilkan sistem yang di harapkan. metode perancangan yang digunakan adalah paradigma prototype model. Model ini mengusulkan sebuah pendekatan kepada pengembangan software yang sistematik dan iteratif mulai dari tingkat kemajuan sistem pada seluruh analisis, desain, kode, pengujian dan pemeliharaan. Metode Prototype ini dapat membantu pengembang dalam memahami lebih baik apa yang akan dikembangkan saat spesifikasi kebutuhan belum jelas, sehingga pengembangan aplikasi menjadi lebih mudah karena pemakai atau pelanggan mengetahui apa yang diharapkannya Paradigma rekayasa perangkat lunak ini diambil dari buku "Rekayasa Perangkat Lunak : Pendekatan Praktisi” tahun 2010 oleh R. S. Pressman.

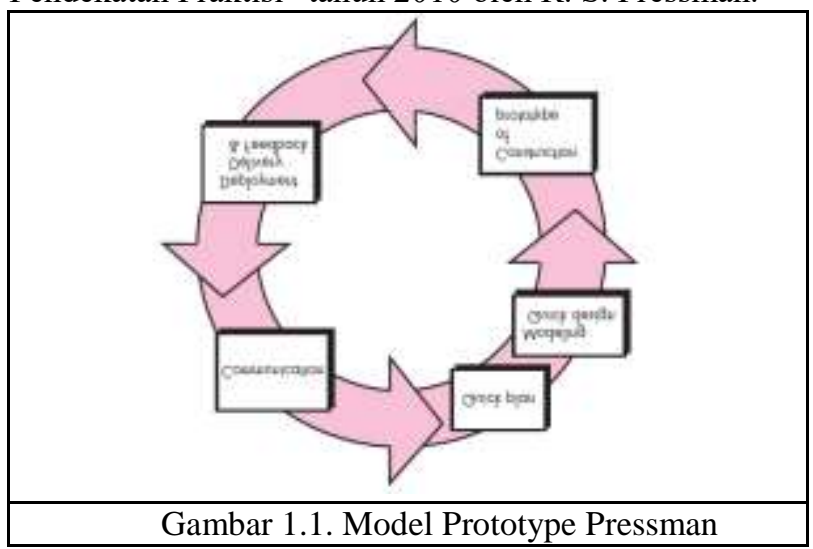

1. Communication

Melakukan konsultasi dengan montir kendaraan motor mengenai sistem kelistrikan dan sistem keamanan kendaraan yang telah ada pada kendaraan. Konsultasi ini dilakukan agar dapat mengetahui jalur kelistrikan mana saja yang aman untuk dilakukan pembukaan dan pemutusan arus. Serta mengidentifikasi spesifikasi kebutuhan.

2. Quick Plan

Melakukan pemodelan sistem dengan membuat sketsa dari arsitektur produk sistem keamanan untuk mengetahui kebutuhan pembangunan sistem dan penerapan modul modul sensor untuk digabungkan dengan mikrokontroler Arduino.

3. Modeling Quick Design

Mengaplikasikan sketsa produk sistem keamanan kedalam bentuk Prototype untuk memodelkan

atau mensimulasikan sistem keamananan selanj utnya di lakukan evaluasi sistem untuk mengetahui tingkat akurasi produk.

4. Contruction of Prototype

Membangun Prototype sistem keamanan dengan membenamkan fungsi fungsi yang akan di gunakan 
menggunakan Arduino IDE kedalam mikrocknt roler Arduino, dan selanjutnya mengkonfigurasi semua komponen seperti, SIM900A, dan Ublox NEO6MV2 pada Arduino.

5. Deployment Delivery \& Feedback

Melakukan uji coba sistem keamanan kendaraan dengan melakukan pengujian black box. Pengujian ini dilakukan pada Prototype rangkaian jaringan kelistrikan kendaraan berupa serangkaian led yang telah disusun sesuai dengan jalur kelistrikan kendaraan. Jika terdapat kekurangan pada program maka akan kembali ke tahap pertama untuk penyempurnaan sistem.

\section{Landasan Teori}

\section{a. Pengertian GPS}

GPS (Global Positioning System) adalah sebuah alat atau sistem yang dapat memberikan sebuah informasi mengenai tata letak atau kebaradaan seseorang yang ada di permukaan bumi.menurut (Winardi, 2006). Mengatakan bahwa GPS adalah sistem untuk menenttukan letak di permukaan bumi dengan bantuan penyelarasan (synchronization) sinyal satelit. Sistem ini menggunakan 24 satelit yang mengirimkan sinyal gelombang mikro ke Bumi. Sinyal ini diterima oleh alat penerima di permukaan, dan digunakan untuk menentukan letak, kecepatan, arah, dan waktu. Sistem yang serupa dengan GPS antara lain GLONASS Rusia, Galileo Uni Eropa, IRNSS India. Sistem GPS, yang nama aslinya adalah NAVSTAR GPS (Navigation Satellite Timing and Ranging Global Positioning System), mempunyai tiga segmen yaitu : satelit, pengontrol, dan penerima / pengguna. Satelit GPS yang mengorbit bumi, dengan orbit dan kedudukan yang tetap (koordinatnya pasti), seluruhnya berjumlah 24 buah dimana 21 buah aktip bekerja dan 3 buah sisanya adalah cadangan.

\section{b. Penentuan Posisi dengan GPS}

Pada dasarnya penentuan posisi dengan GPS adalah pengukuran jarak secara bersama-sama ke beberapa satelit (yang koordinatnya telah diketahui) sekaligus. Untuk menentukan koordinat suatu titik di bumi, receiver setidaknya membutuhkan 4 satelit yang dapat ditangkap sinyalnya dengan baik. Secara default posisi atau koordinat yang diperoleh bereferensi ke global datum yaitu World Geodetic System 1984 atau disingkat WGS'84. Secara garis besar penentuan posisi dengan GPS ini dibagi menjadi dua metode yaitu metode absolut dan metode relatif.

1) Metode absolut atau juga dikenal sebagai precise point positioning, menentukan posisi hanya berdasarkan pada 1 pesawat penerima (receiver) saja. Ketelitian posisi dalam beberapa meter (tidak berketelitian tinggi) dan umumnya hanya diperuntukkan bagi keperluan navigasi.

2) Metode relatif atau sering disebut differential positioning, menetukan posisi dengan menggunakan lebih dari sebuah receiver. Satu GPS dipasang pada lokasi tertentu dimuka bumi dan secara terus menerus menerima sinyal dari satelit dalam jangka waktu tertentu dijadikan sebagai referensi bagi yang lainnya. Metode ini menghasilkan posisi berketelitian tinggi (umumnya kurang dari 1 meter) dan diaplikasikan untuk keperluan survei geodesiataupun pemetaan yang memerlukan ketelitian tinggi.

\section{c. SMS Gateway}

SMS gateway adalah sebuah perangkat yang menawarkan layanan transit SMS, mentransformasikan pesan ke jaringan selular dari media lain, atau sebaliknya, sehingga memungkinkan pengiriman atau penerimaan pesan SMS dengan atau tanpa menggunakan ponsel. Sebagaimana penjelasan diatas, SMS gateway dapat terhubung ke media lain seperti perangkat SMSC dan server milik Content Provider melalui link IP untuk memproses suatu layanan SMS. Sebuah sistem SMS gateway, umumnya terdiri komponen hardware (server/komputer yang dilengkapi dengan perangkat jaringan) dan software (aplikasi yang digunakan untuk pengolahan pesan). Dan untuk sebuah sistem yang besar umumnya menggunakan database untuk penyimpanan data .

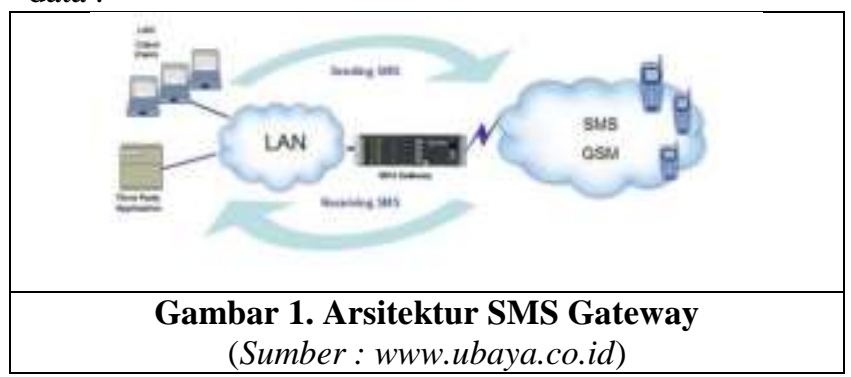

\section{d. Modul GSM SIM 900 A}

SIM900A adalah salah satu produk GSM/GPRS Serial Modem dari SIMCOM yang dapat kita gunakan bersama microcontroller Arduino baik untuk tur SMS,Telefon ataupun data GPRS.Berikut Spesikasi singkat Module Chip SIM900A :

-Quad-Band 850 / 900/ 1800 / $1900 \mathrm{MHz}$

-GPRS multi-slot class 10/8

-GPRS mobile station class B

-Compliant to GSM phase $2 / 2+$

-Class 4 (2 W (AT) $850 / 900 \mathrm{MHz}$ )

-Class 1 (1 W (AT) $1800 / 1900 \mathrm{MHz})$

-Perintah menggunakan AT Command

- Standard Commands: GSM 07.07 \& 07.05 | Enhanced Commands: SIMCOM AT

- Embedded TCP/UDP stack - Dapat Upload data ke web server

-Support RTC

-Pemilihan Port Serial (3.3V dan 5V Level)

-Terdapat Jack speaker dan headphone (type breakout board tertentu)

-Konsumsi daya rendah - $1.5 \mathrm{~mA}$ (sleep mode)

-Bekerja pada temperatur - $-40 \mathrm{C}$ to $+85 \mathrm{C}$ 


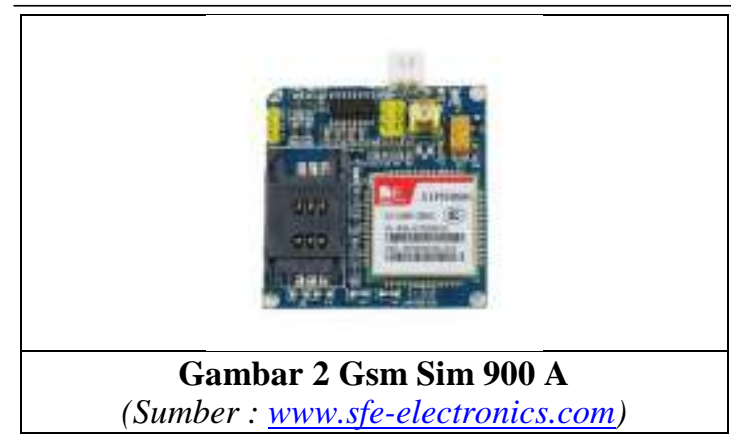

\section{e. Modul Relay}

Modul relay ini dapat digunakan sebagai switch untuk menjalankan berbagai peralatan elektronik. Misalnya Lampu listrik, Motor listrik, dan berbagai peralatan elektronik lainnya.Kendali ON / OFF switch (relay), sepenuhnya ditentukan oleh nilai output sensor, yang setelah diproses Mikrokontroler akan menghasilkan perintah kepada relay untuk melakukan fungsi ON / OFF Kontak Poin (Contact Point) Relay terdiri dari 2 jenis yaitu :

1. Normally Close (NC) yaitu kondisi awal sebelum diaktifkan akan selalu berada di posisi CLOSE (tertutup)

2. Normally Open (NO) yaitu kondisi awal sebelum diaktifkan akan selalu berada di posisi OPEN (terbuka)

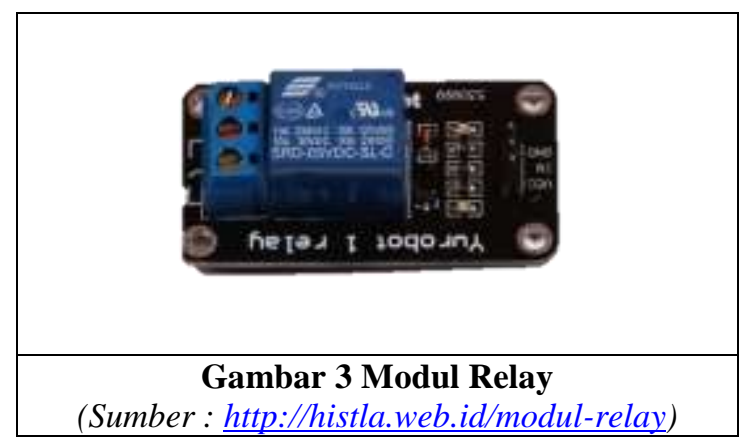

\section{f. Arduino USB}

Menggunakan USB sebagai antar muka pemrograman atau komunikasi komputer.

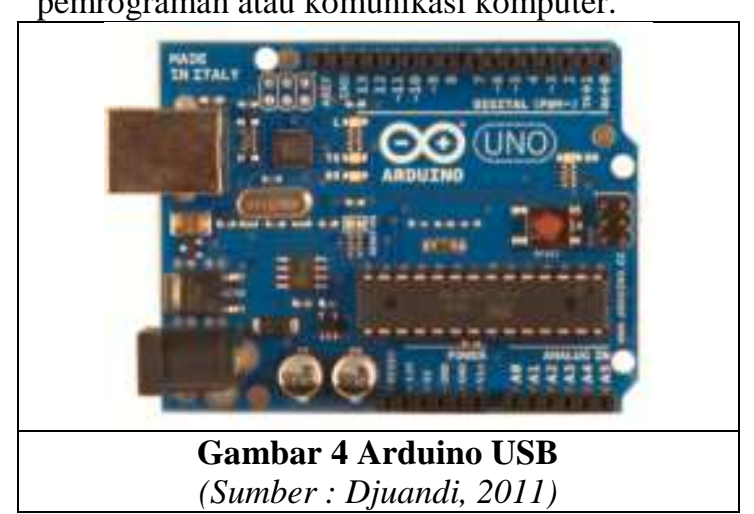

Uno adalah yang terbaru dalam serangkaian board USB Arduino, dan sebagai model referensi untuk platform Arduino, untuk perbandingan dengan versi sebelumnya, lihat indeks board Arduino.

Adapun data teknis yang terdapat board Arduino UNO adalah sebagai berikut:

1. Mikrokontroler: ATmega328
2. Tegangan Operasi: $5 \mathrm{~V}$

3. Tegangan Input (recommended): $7-12 \mathrm{~V}$

4. Tegangan Input (limit): 6-20 V

5. Pin digital I/O: 14 (6 diantaranya pin PWM)

6. Pin Analog input: 6 input pin

7. Arus DC per pin I/O: $40 \mathrm{~mA}$

8. Arus DC untuk pin $3.3 \mathrm{~V}: 150 \mathrm{~mA}$

9. Flash Memory: $32 \mathrm{~KB}$ dengan $0.5 \mathrm{~KB}$ digunakan sebagai bootloader

10. SRAM: $2 \mathrm{~KB}$

11. EEPROM: $1 \mathrm{~KB}$

12. Kecepatan besaran waktu sebesar: $16 \mathrm{Mhz}$ sebagai komponen untuk (Crystall oscillator)

\section{g. Pengertian App Inventor}

App Inventor for Android atau Google App Inventor, itulah namanya, aplikasi berbasis web open source yang awalnya dikembangkan oleh Google, dan saat ini dikelola oleh Massachusetts Institute of Technology (MIT). App Inventor memungkinkan pengguna baru untuk memprogram komputer untuk menciptakan aplikasi perangkat lunak bagi sistem operasi Android. App Inventor ini menggunakan antarmuka grafis, serupa dengan antarmuka pengguna pada Scratch, yang memungkinkan pengguna men-dragand-drop objek visual untuk menciptakan aplikasi yang bisa dijalankan pada perangkat Android. Begitupun dengan coding, kita tidak perlu menulis kode program yang amat sangat panjang, cukup dengan men-drag-anddrop seperti halnya menyusun puzzle.

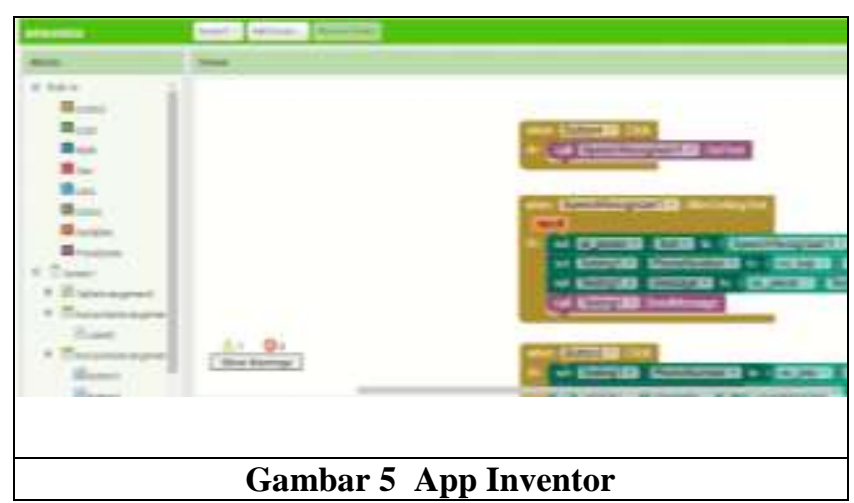




\section{ANALISIS DAN PERANCANGA SISTEM}

\section{a. Analisis Arsitektur Sistem}

Analisis arsitektur sistem adalah tahapan untuk mendapatkan gambaran umum sistem yang akan dibangun.

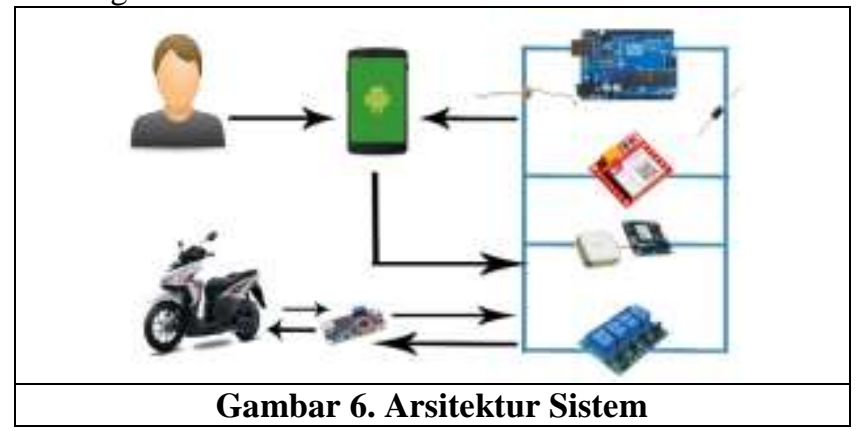

Gambar di atas menggambarkan sistem yang akan dibangun, dimana user akan menggunakan alat kemanan bermotor melalui perangkat android, kemudian mikrokontroler akan menjalankan perintah yang telah di berikan oleh user melalui Modul GSM dan sistem keamanan pada motor dapat di jalankan. Untuk arus listrik diambil dari aki motor yang akan di coverter melalui USB charger Motor yang menghasilkan tegangan $5 \mathrm{~V}$ pada mikrokontroler arduino

\section{b. Pemodelan Sistem}

Pemodelan sistem merupakan gambaran mengenai sistem yang akan dibuat mulai dari cara kerja hingga ke antar muka pengguna. Pada penelitian tugas akhir ini ada dua perancangan yang dilakukan yaitu perancangan hardware untuk menggabungkan antara Mikrokontroler arduino dan modul - modul sensor, dan perancangan software untuk pembuatan aplikasi mobile yang di gunakan untuk menjalakan mikrokontroler arduino.

\section{c. Pemodelan Hardware}

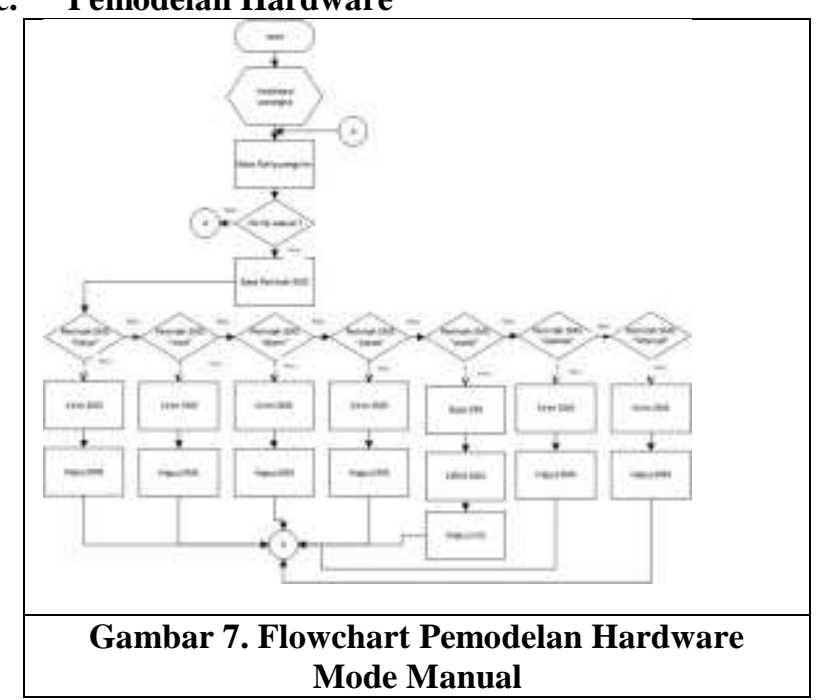

\section{Keterangan}

Ketika mode operasi diaktifkan maka proses yang akan dilakukan pada kendaraan motor harus dilakukandengan menggunakan aplikasi mobile dikarena pada saat mode operasi diaktikan arus listrik yang ada pada kendaraan akan dihambat oleh sebuah relay dan akan aktif ketika perintah yang di masukan oleh pengguna melalui aplikasi mobile dilakukan. ketika mode manual diaktifkan maka proses yang dilakukan pada kendaraan motor dapat dilakukan dengan dua cara yaitu dapat dilakukan langsung pada motor tersebut atau dapat dilakukan pada perintah yang dimasukan oleh apilkasi mobile.

Tabel 1. Kode Perintah

\begin{tabular}{|l|lr|}
\hline Kode perintah & Keterangan \\
\hline Hidup & $\begin{array}{l}\text { Perintah untuk } \\
\text { mengaktifkan kendaraan }\end{array}$ \\
\hline Mati & $\begin{array}{l}\text { Perintah untuk } \\
\text { menonaktifkan kendaraan }\end{array}$ \\
\hline Lokasi & $\begin{array}{l}\text { Perintah yang dilakukan } \\
\text { untuk mengetahui posisi } \\
\text { kendaraan }\end{array}$ \\
\hline Panas & $\begin{array}{l}\text { Perintah yang dilakukan } \\
\text { pada saat akan } \\
\text { memanaskan kendaraan }\end{array}$ \\
\hline Alarm & $\begin{array}{l}\text { Perintah untuk } \\
\text { mengaktifkan alarm pada } \\
\text { kendaraan }\end{array}$ \\
\hline Operasi & $\begin{array}{l}\text { Perintah untuk } \\
\text { mengaktifkan } \\
\text { operasi }\end{array}$ \\
\hline Manual & $\begin{array}{l}\text { Perintah mode } \\
\text { mengaktifkan } \\
\text { manual }\end{array}$ \\
\hline
\end{tabular}

\section{d. Pemodelan Software}

Pemodelan Software dilakukan dengan Flowchart sebagai diagram untuk memvisualisasi, menspesifikasikan, membangun, dan pendokumentasian sistem yang dibuat. Berikut merupakan Flowchart Diagram dari sistem keamanan kendaraan.

\section{Flowchart Diagram Voice}

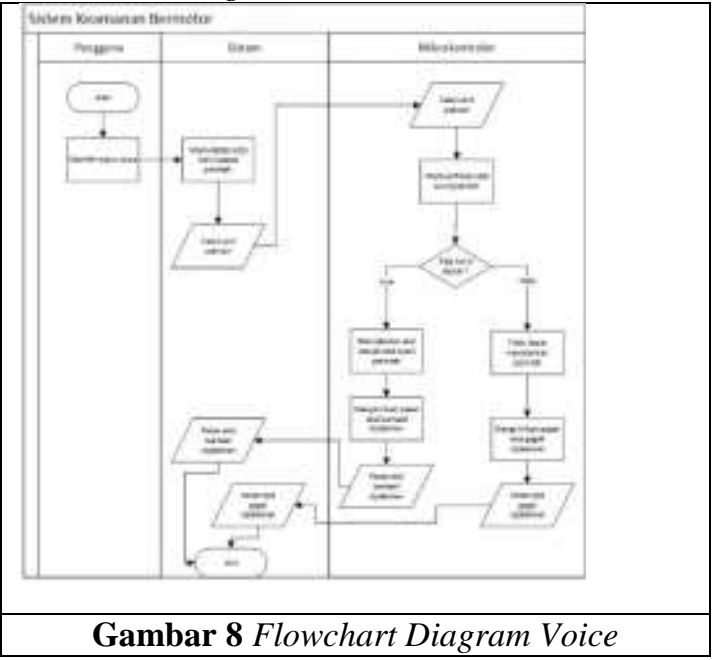

2. Flowchart Diagram Cek Keberadaan Motor 
Hasbu Naim Syaddad, Perancangan Sistem Keamanan Sepeda Motor Menggunakan Gps Tracker Berbasis Mikrokontroler Pada Kendaraan Bermotor
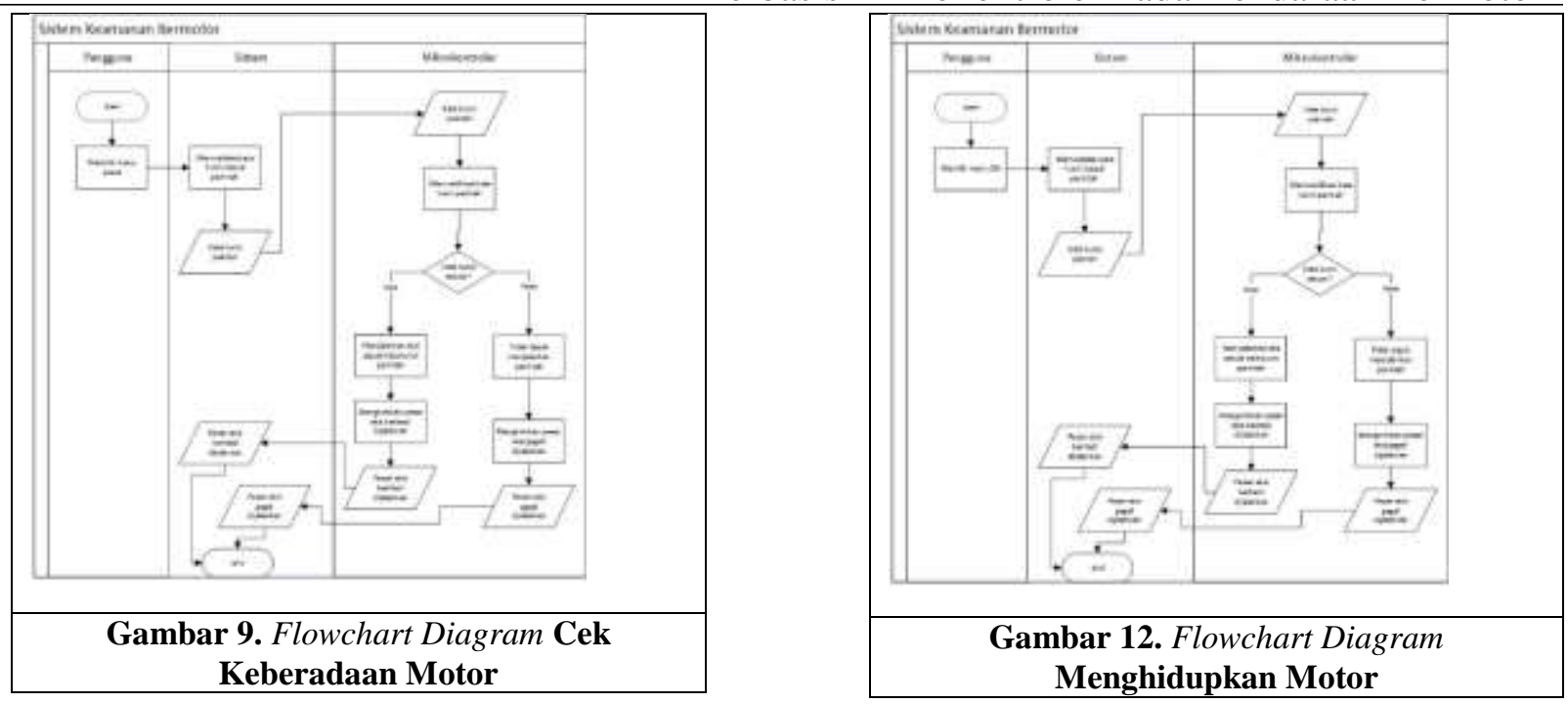

3. Flowchart Diagram Pemanasan Motor

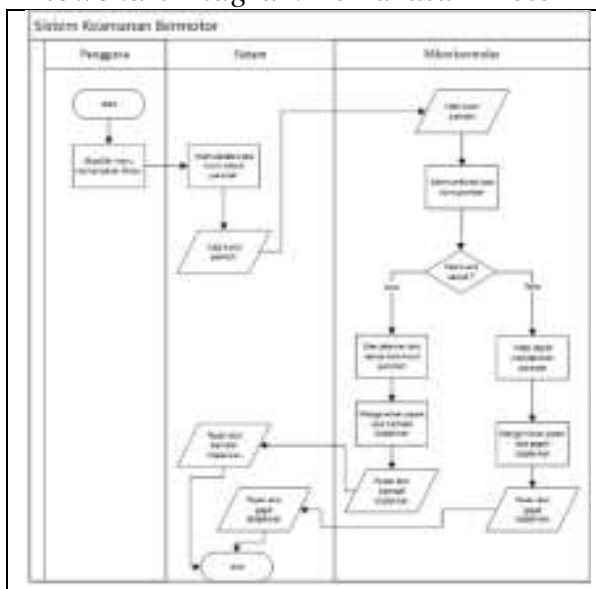

Gambar 10 Flowchart Diagram Pemanasan Motor

4. Flowchart Diagram Menonaktifkan Motor

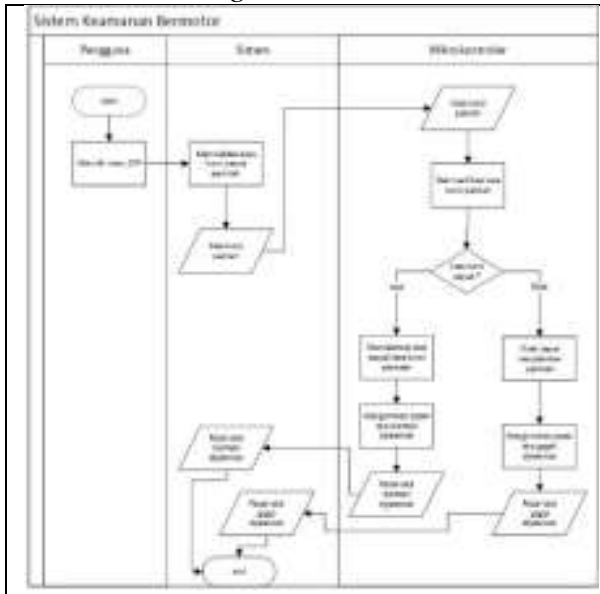

Gambar 11. Flowchart Diagram Menonaktifkan Motor

5. Flowchart Diagram Menghidupkan Motor

6. Flowchart Diagram alarm motor

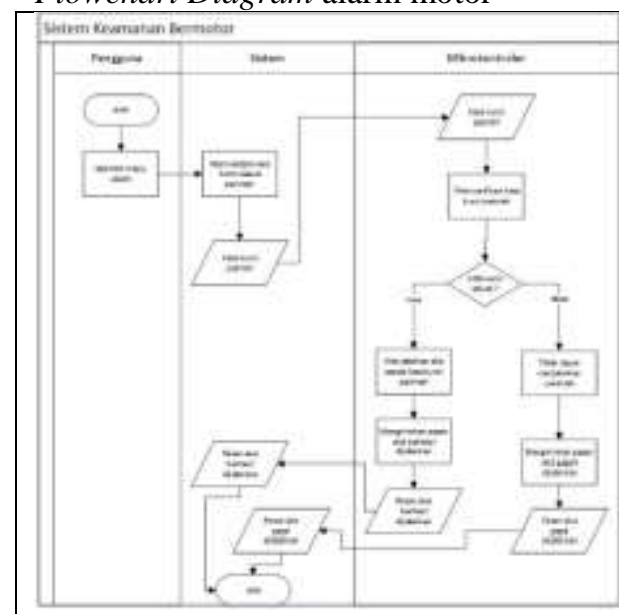

Gambar 13. Flowchart Diagram Alarm Motor

7. Flowchart Diagram Operasi

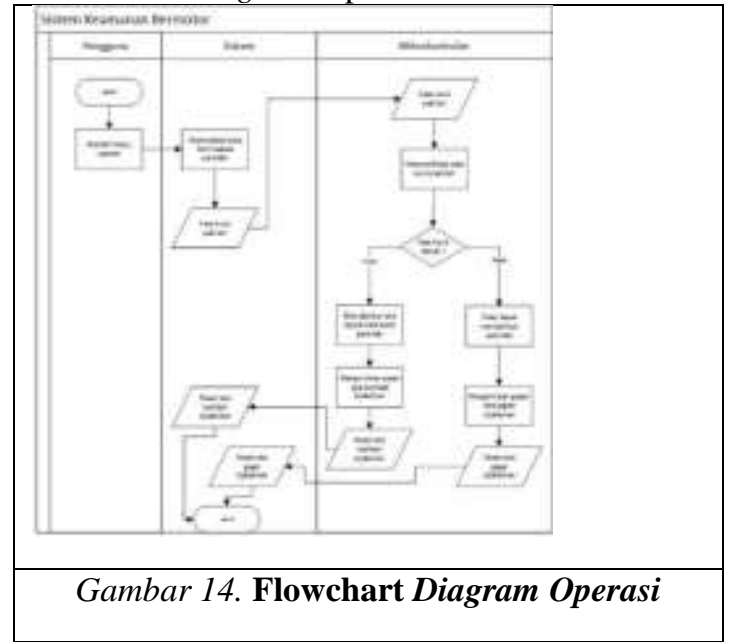

8. Flowchart Diagram Manual 


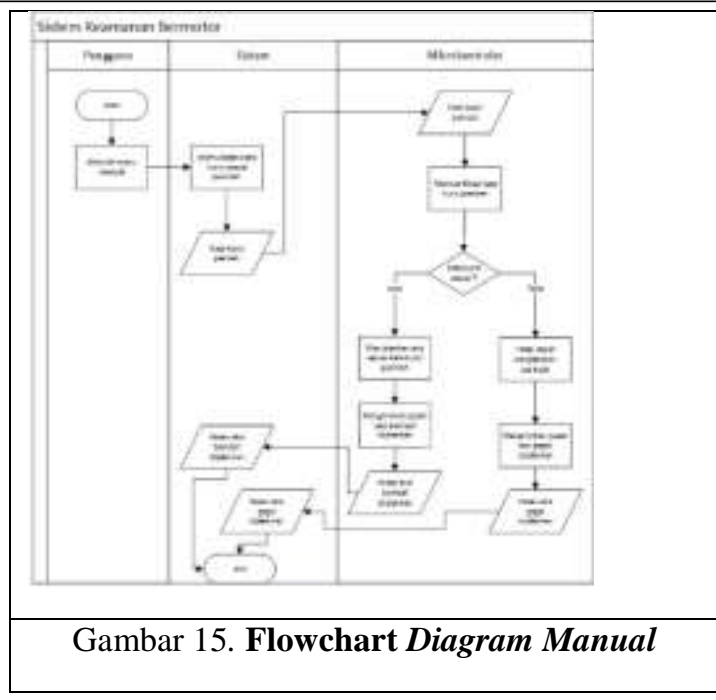

\section{e. Perancangan Sistem}

Perancangan sistem ini akan membahas mengenai perancangan pada software dan hardware perancangan antar muka. Pada perancangan sofware akan membahas tentang perancangan anatar muka dan untuk hardware akan membahas tentang perancangan mikrokontroler dan komunikasi antar modul.

\section{1) Perancangan Antarmuka}

Perancangan Antarmuka merupakan bagian dari pembuatan sistem keamanan kendaraan karena digunakan untuk menjembatani antara interaksi manusia dan sistem. berikut ini merupakan perancangan antarmuka untuk Android yang akan dibuat.

\section{Halaman Utama}

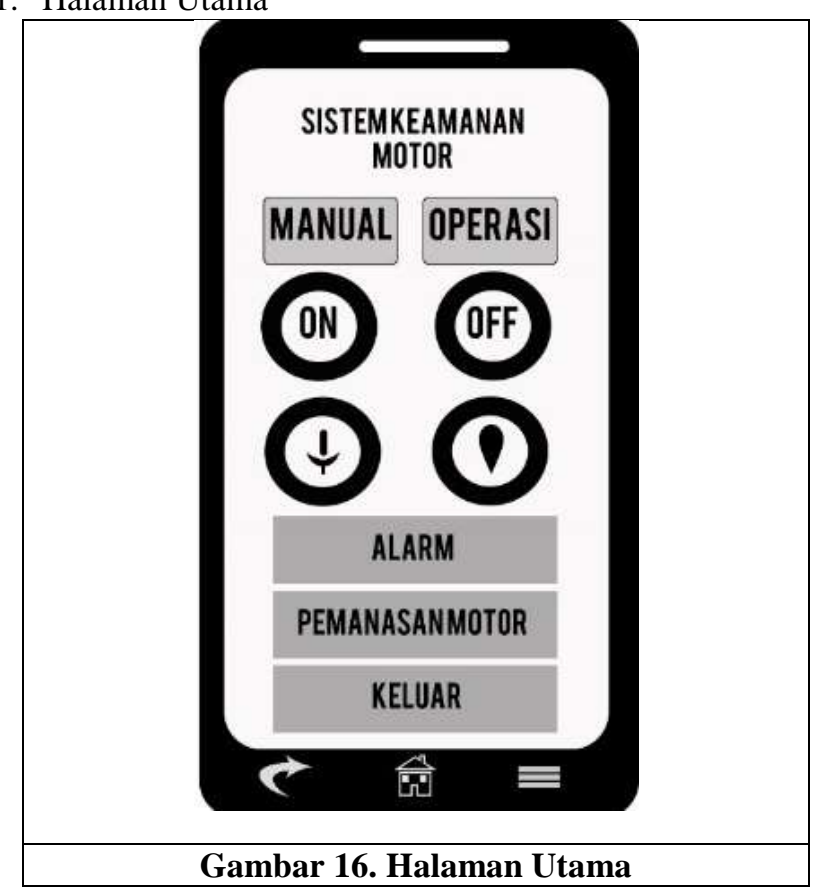

Perancangan Mikrokontroler Arduino

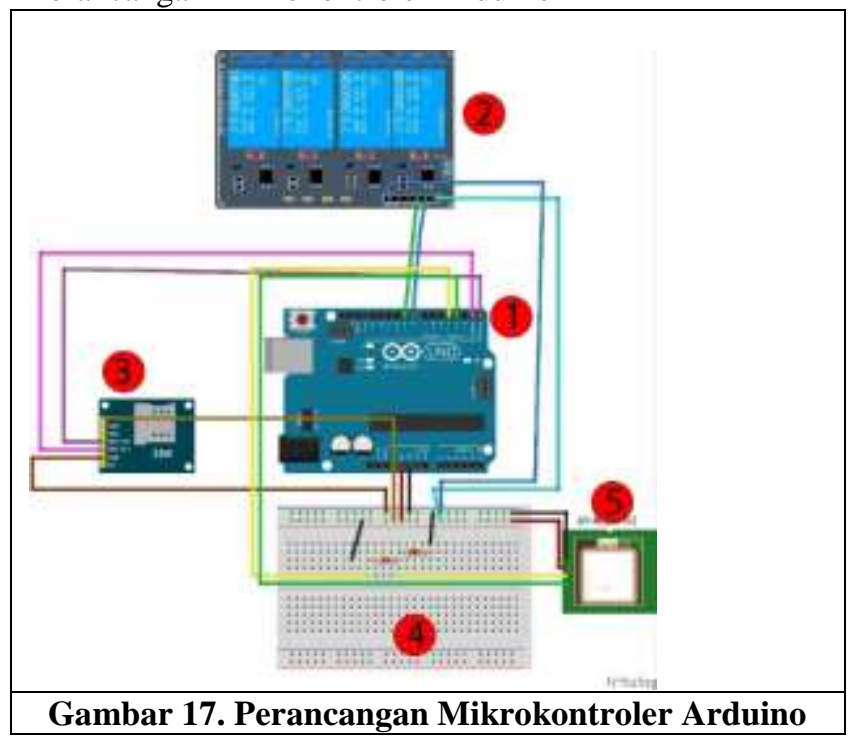

\section{Keterangan}

Pada Perancangan mikrokontroler arduino diatas tedapat beberapa modul yang saling terhubung diantaranya

1. Arduino Uno

2. Relay

3. Modul SIM

4. Bread Borard

5. Modul GPS

\section{f. Analisis Komunikasi Perangkat}

Analisis komunikasi Perangkat merupakan gambaran komunikasi antar satu perangkat dengan perangkat lainnya sehingga sistem ini terintegrasi satu sama lain. Komunikasi Perangkat yang akan dijelaskan adalah komunikasi perangkat mikrokontroller.

\section{1) Analisis Komunikasi Perangkat Mikrokontroler}

Analisis komunikasi perangkat merupakan gambaran antar mikrokontroler dengan perangkat lainnya sehingga sistem bisa terhubung satu sama lain

1. Komunikasi Arduino UNO dengan Modul GSM SIM 900 A Arduino

Berkomunikasi dengan sensor modul gsm sim 900 A melalui pin 2, pin 3, 5V, GND. Untuk lebih jelasnya dapat dilihat pada gambar di bawah ini.

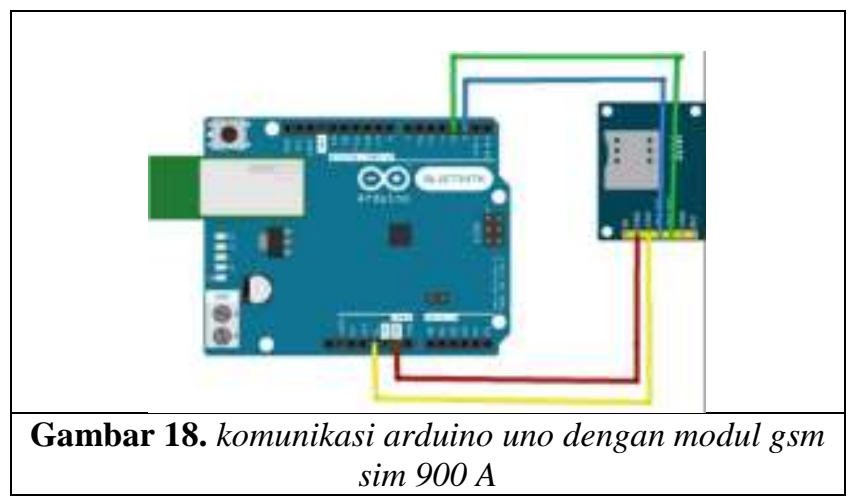

2. Komunikasi Arduino UNO dengan Modul Relay 
Hasbu Naim Syaddad, Perancangan Sistem Keamanan Sepeda Motor Menggunakan Gps Tracker Berbasis Mikrokontroler Pada Kendaraan Bermotor

Arduino berkomunikasi dengan sensor modul relay melalui pin 9,10,11,12 5V, GND. Untuk lebih jelasnya dapat dilihat pada gambar di bawah ini

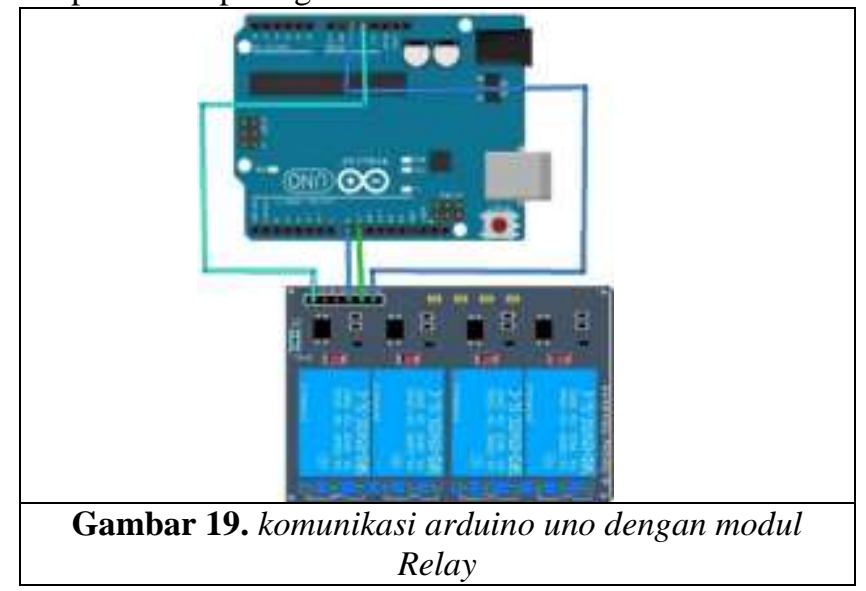

3. Komunikasi Arduino UNO dengan Modul Ublox Neo 6m

Arduino berkomunikasi dengan sensor modul Ublox Neo $6 \mathrm{~m}$ melalui pin 7,pin 8 sebagi serial pin, $5 \mathrm{~V}$, GND. Untuk lebih jelasnya dapat dilihat pada gambar di bawah ini

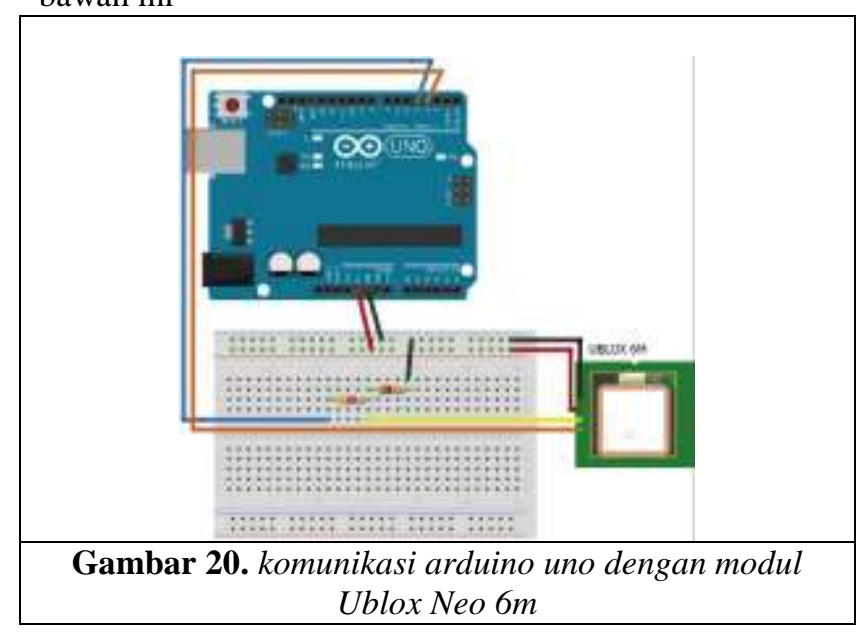

\section{Implementasi Danpengujian Sistem}

a. Implementasi Antarmuka

1. Aplikasi Mobile

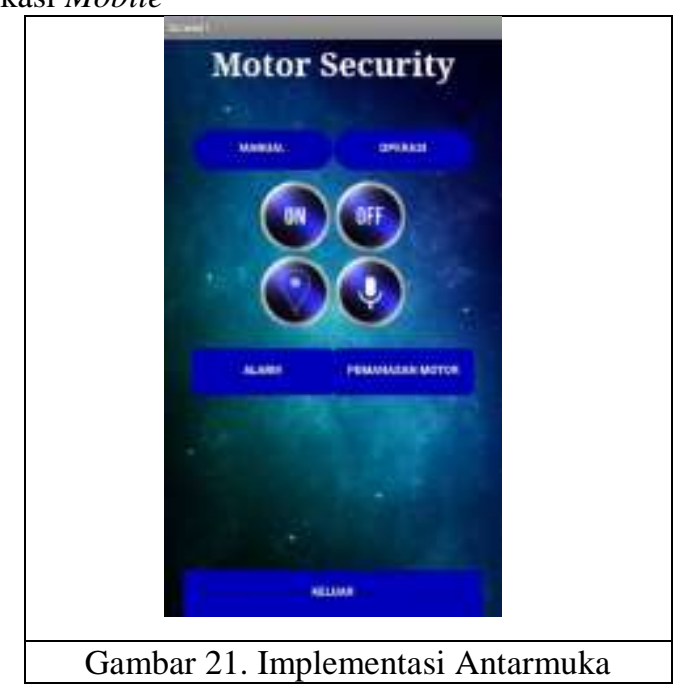

2. Implementasi Hardware Arduino Sistem Keamanan bermotor
Tahap implementasi ini merupakan tahap penerapan atau perakitan Arduino Sistem Monitoring Area Parkir dan komponen pendukung lainnya.

Perakitan Arduino Sistem Keamanan Bermotor

1. Perakitan Sistem Keamanan kendaraan

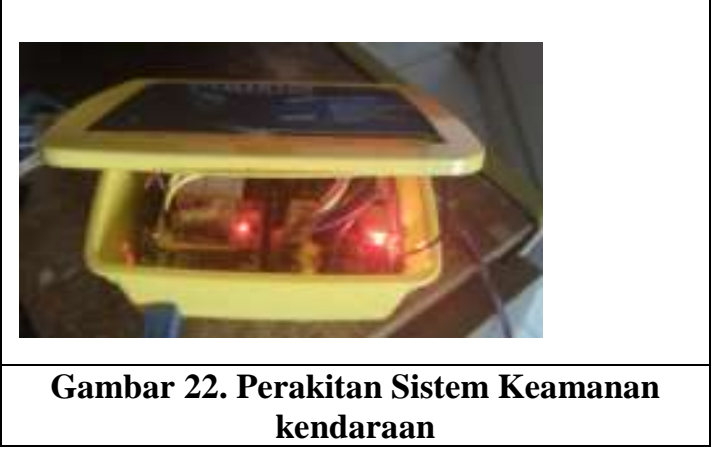

1. Perakitan SIM $900 \mathrm{~A}$

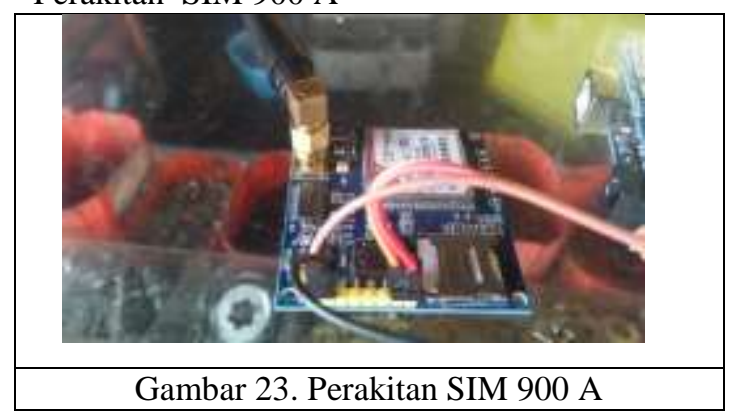

Keterangan

Tabel 2 mplementasi Pengkabelan Sim 900 A

\begin{tabular}{|l|l|}
\hline \multicolumn{2}{|c|}{ Modul Sim 900 A } \\
\hline Pin Arduino & Pin Modul \\
\hline VCC & $5 \mathrm{~V}$ \\
\hline GND & GND \\
\hline RX & 2 \\
\hline TX & 3 \\
\hline
\end{tabular}

2. Perakitan GPS Ublox Neo6M

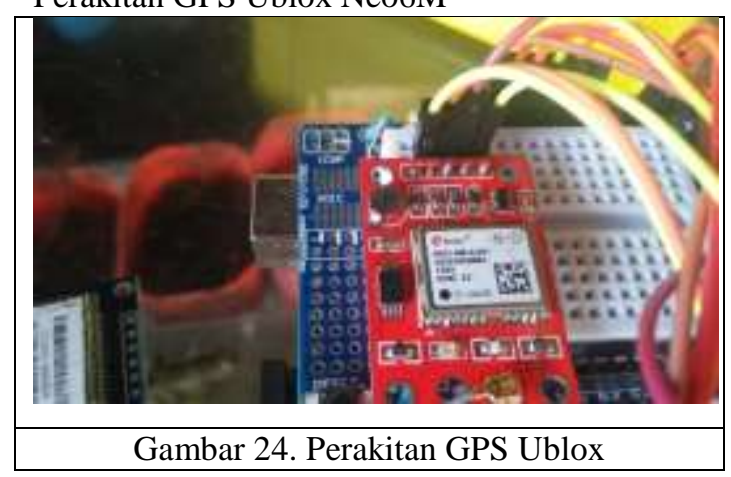

Keterangan

Tabel 3 Implementasi Pengkabelan Sim 900 A

Modul Sim 900 A 


\begin{tabular}{|l|l|}
\hline Pin Arduino & Pin Modul \\
\hline VCC & $5 \mathrm{~V}$ \\
\hline GND & GND \\
\hline RX & 7 \\
\hline TX & 8 \\
\hline
\end{tabular}

3.2 Pengujian Pembacaan Data Modul GPS

1. Pengujian Pengambilan Data GPS pada Kendaraan

Pengujian ini bertujuan mengambil data pembacaan data GPS dengan kondisi alat dipasang pada kendaraan. Dari hasil pembacaan GPS akan dihitung jarak perpindahan titik GPS menggunakan metode Euclidean Distance. Pada setiap pembacaan titik koordianat baru, maka mikrokontroler akan menghitung jaraknya dari titik koordinat kendaraan

3. Perakitan Relay

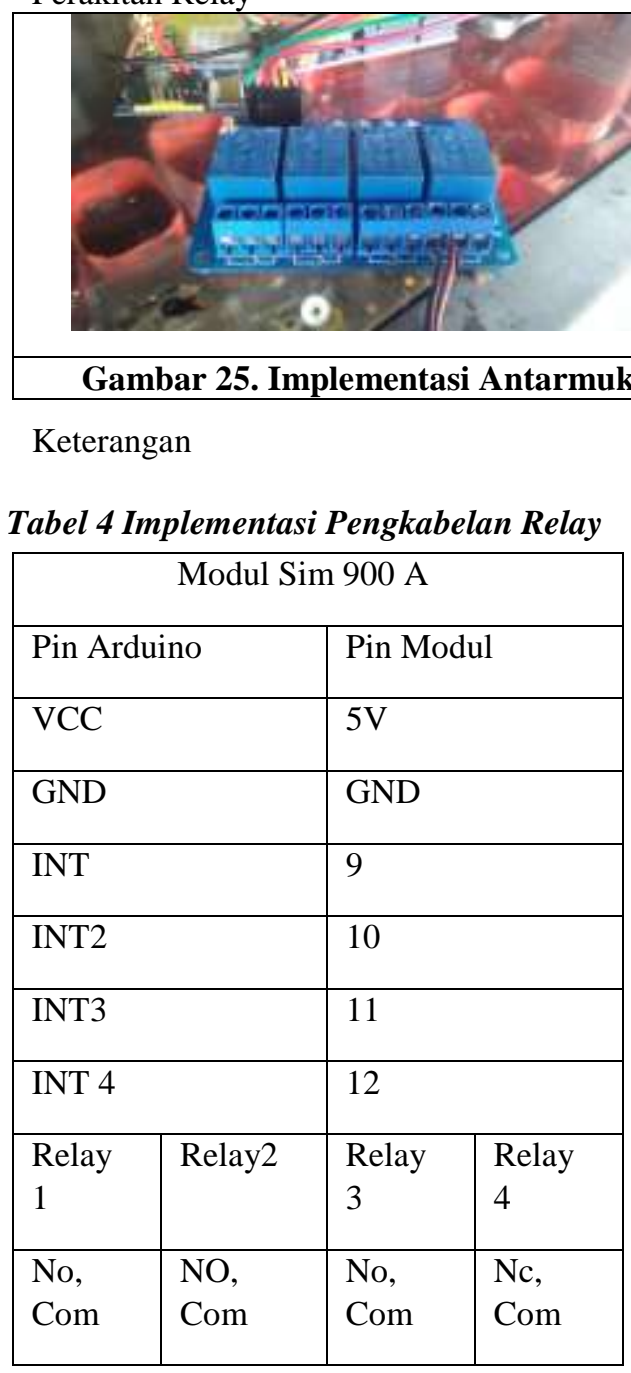
diparkirkan.

Tabel 6 Pengujian Pengambilan Data GPS pada Kendaraan

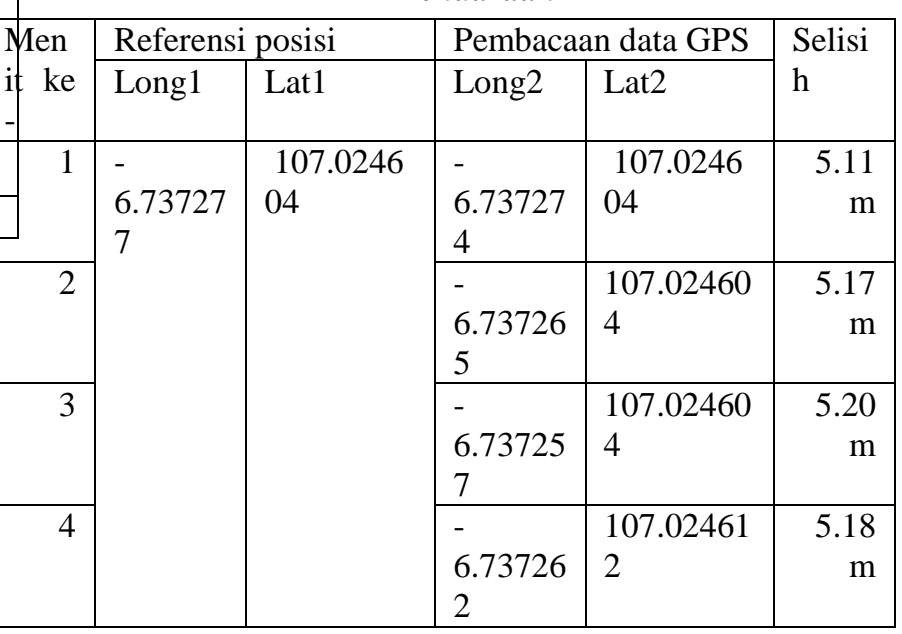

Pengujian Perhitungan Jarak Dua Data GPS

Perhitungan jarak dua data GPS dengan menggunakan metode Euclidean Distance sebagai berikut:

$$
\sqrt{\begin{array}{c}
((-6.737277)-(-6.737274)) 2 \\
+ \\
((107.024604)-(107.024604)) 2^{x}
\end{array}}
$$

Jarak $=0,000000205 \times 11.319$

Jarak $=0.000452 \times 11.319$

Jarak $=0,005116188 \mathrm{Km}$

Jarak $=5,11 \mathrm{~m}$

Pengujian ini bertujuan untuk mengetahui waktu yang diperlukan dalam proses mengirim dan menerima pesan SMS pada setiap perintah SMS yang dikirim oleh pemilik ke mikrokontroler

Table 5 Pengujian Perintah SMS

\begin{tabular}{|l|c|c|c|c|c|c|c|}
\hline \multicolumn{7}{|c|}{ Waktu Respon (s) } \\
\hline $\begin{array}{l}\text { Perco } \\
\text { baan } \\
\text { Ke }\end{array}$ & $\begin{array}{c}\text { Pos } \\
\text { isi }\end{array}$ & $\begin{array}{c}\text { Hid } \\
\text { up }\end{array}$ & $\begin{array}{c}\text { M } \\
\text { ati }\end{array}$ & $\begin{array}{c}\text { Pan } \\
\text { as }\end{array}$ & $\begin{array}{c}\text { ala } \\
\text { rm }\end{array}$ & $\begin{array}{c}\text { man } \\
\text { ual }\end{array}$ & $\begin{array}{c}\text { Ope } \\
\text { rasi }\end{array}$ \\
\hline 1 & 5 & 4 & 4 & 4 & 5 & 3 & 4 \\
\hline 2 & 8 & 4 & 4 & 4 & 4 & 5 & 5 \\
\hline 3 & 8 & 3 & 3 & 5 & 4 & 6 & 5 \\
\hline 4 & 5 & 3 & 4 & 5 & 4 & 5 & 5 \\
\hline 5 & 8 & 5 & 3 & 4 & 4 & 5 & 4 \\
\hline
\end{tabular}

\section{Gambar 26 Perhitungan Jarak dalam Google Map}

\subsection{Pengujian Modul GPS Sebagai Sensor Posisi}

Pengujian Modul GPS Sebagai Sensor Posisi Pengujian ini bertujuan untuk menguji modul GPS berkerja maksimal sebagai sensor posisi. Yang diukur adalah jarak dari pembacaan data GPS dengan 
Hasbu Naim Syaddad, Perancangan Sistem Keamanan Sepeda Motor Menggunakan Gps Tracker

Berbasis Mikrokontroler Pada Kendaraan Bermotor

referensi data GPS yang disimpan pada saat awal kendaraan diparkir.

Tabel 7 Pengukuran Sensor Posisi Aktif

\begin{tabular}{|l|l|l|}
\hline $\begin{array}{l}\text { Percobaa } \\
\mathrm{n} \text { ke - }\end{array}$ & $\begin{array}{l}\text { Jarak Sensor } \\
\text { Aktif }(\mathrm{m})\end{array}$ & $\begin{array}{l}\text { SMS } \\
\text { Peringatan }\end{array}$ \\
\hline 1 & 65 & Aktif \\
\hline 2 & 75 & Aktif \\
\hline 3 & 45 & Aktif \\
\hline
\end{tabular}

Berikut merupakan tampilan Link pada google map yang diterima dari Mikrokontroler

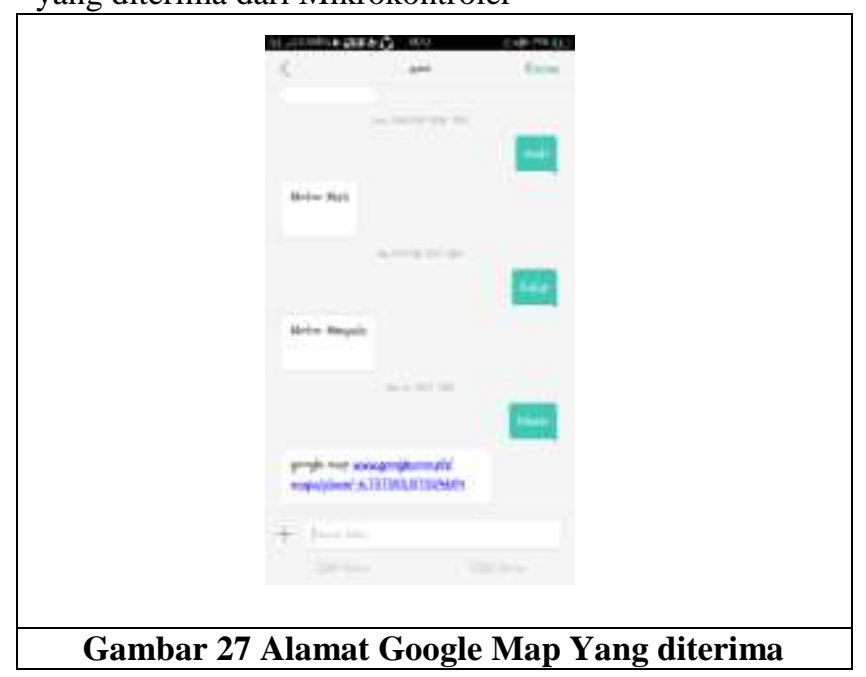

Sistem berhasil mengirimkan perintah kemudian menerima balasan berupa link Google Maps. Berikut adalah tampilan ketika link Google maps dibuka.

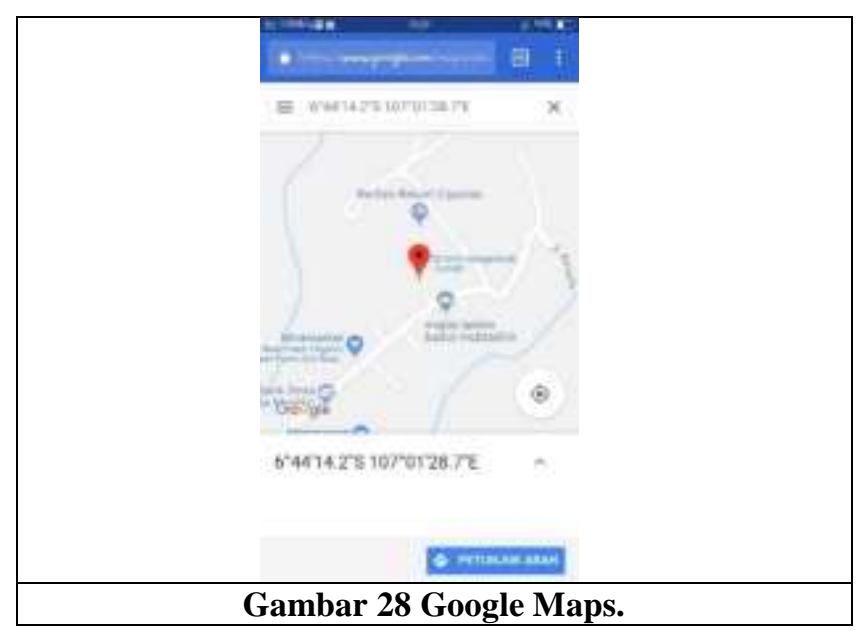

\section{Simpulan dan Saran}

Berdasarkan hasil penelitian, perancangan dan implementasi yang dilakukan, dapat diambil beberapa kesimpulan, antara lain :

1. Telah selesai dibuat Sistem Keamanan Kendaraan Dengan Metode Precise Point Positioning Untuk Pencarian Posisi Kendaraan Menggunakan GPS Tracker Berbasis Mikrokontroler

2. Sistem keamanan kendaraan berhasil dibuat agar dapat mengetahui posisi kendaraan serta pengendalian kendaraan dari jarak jauh
3. Tracking system telah berhasil diterapkan pada sistem keamanan dengan hasil presisi yang akurat.

4. Sistem keamanan kendaraan berhasil telah berhasil dipasangkan pada kendaraan bermotor

Pada penelitian tugas akhir ini terdapat beberapa saran untuk dapat

meningkatkan fungsionalitas sistem keamanan bagi pengguna dari sistem

keamanan kendaraan yang telah diselesaikan.

1. Dilakukan pengembangan untuk dapat menampung rute perjalan yang telah dilewati

2. Pembuatan alat dengan perancangan pada PCB agar ukuran alat yang digunakan lebih kecil

\section{Daftar Pustaka}

[1]. Chonoles. (2003). UML 2 for Dummie. New York: Wiley Publishing.

[2]. Djuandi, F. (2011). Pengenalan Arduino.

[3]. https://blogs.itb.ac.id/. (2014, September Selasa). Diambil kembali dari teori pengukuran jarak:

https://blogs.itb.ac.id/anugraha/2014/09/10/teoripengukuran-jarak/

[4]. Jogiyanto. (2005). Analisis dan Desain Sistem Informasi. Yogyakarta: Andi.

[5]. membuat aplikasi android lebih mudah dengan

[6]. Pressman, R. S. (2010). Rekayasa Perangkat Lunak. Yogyakarta: ANDI.

[7]. Setiawan, A. (2011). Mikrokontroler ATMEGA 8535 \& ATMEGA16 menggunakan BASCOM$A V R$. Yogyakarta: Andi.

[8]. Wahana Komputer. (2005). Pengembangan Aplikasi Sistem Informasi Akademik Berbasis SMS dengan Java. Jakarta: Salemba Infotek. 